\title{
A Mechanical Dissection Laboratory using KitchenAid Mixers
}

\author{
Ted Hubbard, Darrel Doman, Craig Arthur \\ Mechanical Engineering Department \\ Dalhousie University, Halifax, Nova Scotia, \\ Canada, B3J 2X4 \\ ted.hubbard@dal.ca
}

\begin{abstract}
This paper presents the development of a Mechanical Dissection Laboratory at Dalhousie University using KitchenAid stand mixers. In addition to a reputation for durability, the mixers are very well designed mechanically, and thus serve as an excellent teaching tool for Machine Design. The mixers contain a large number of robust and relevant components, covering almost all of the topics discussed in most Machine Design courses. In this lab students are introduced to topics such as electric motors, planetary gears, helical and spur gears, worm gears, bevel gears, shafts and couplers. Students work in small groups of approximately three; they are provided with a tool kit, as well as a disassembly manual. After a short safety introduction, the students disassemble the device, taking measurements as they proceed. They then reassemble the device, and test that it is in complete working order.
\end{abstract}

\section{Introduction}

Dissection: What is it?

Dr. Joseph E. Shigley [1] had an elegantly simple take on what design is: "A design problem is not a hypothetical problem at all. Design has an authentic purpose - the creation of an end result by taking definite action ...". Shigley believed that engineering design is rooted in taking physical action, in doing rather than observing. Dissection is the practice of disassembling a real-world part in order to investigate the engineering principles at work. Since students must actively dissect the part they are essentially performing design in reverse. This is particularly useful educationally as it gives students the ability to answer important design questions such as "how did others solve the problem" and "why the solution works".

Dissection has many academic benefits that are both direct and indirect on the formation of a designoriented engineering student. Dr. Sheri D. Sheppard, at
Stanford University, has run a very successful mechanical dissection laboratory [2] and gives many examples of student impact. Foremost is an awareness of the design process; students realize that products do not just appear and that design involves many tradeoffs amongst the possible solutions. The practical benefits are numerous as well, where students gain valuable 'hands-on' experience as many engineering students have little experience in this area.

Also, the dissection gives students and opportunity to examine other people's solution to a problem. According to Sheppard it is during this examination that the instructor can prompt the students to reason out why the design's form and function is the way it is.

\section{KitchenAid Stand Mixers}

KitchenAid stand mixers have been available since the 1920's. Unlike other common household appliances that have simple or no gearing (e.g. blenders and hand mixers) stand mixers have multiple gear stages. In addition, they often feature a power take off (PTO) for attachments/accessories. The parts are large and robust due to the fact that unlike many small appliances, they are intended to be repaired, and as such the design is made to be disassembled and reassembled. KitchenAid stand mixers offer a number of advantages in a Mechanical Engineering Laboratory context:

1. Few devices have the sheer variety of interconnected mechanical components that are found in the stand mixers.

2. Most of the parts are large and robust; this makes them easy for students to manipulate and measure, as well as difficult for students to lose or damage.

3. The cost per setup is moderate ( $\$ 400-700 \mathrm{CDN})$ and the parts are expected to have a long life span.

KitchenAid mixer models come in a range of sizes and wattage ratings: models range from the entry level Classic to the mid level Artisan to the higher level Accolade and Professional. Mid-range prices are typically in the $\$ 400 \mathrm{CDN}$ range, although lighter duty 
models can sometimes be found for $\$ 200 \mathrm{CDN}$, and more expensive models can be $\$ 600+\mathrm{CDN}$. The KitchenAid website (http://www.kitchenaid.ca [3]) provides general information on the different models and well as more technical information. For example parts lists and pdf versions of exploded parts diagrams are usually found in the customer care or support sections, although they can be hard to locate unless you know the model number.

For this dissection laboratory, we purchased two types of stand mixers: the heavier duty Accolade and the lighter duty Artisan. While generally similar, there are some notable mechanical differences between these models. There three major differences are: gearing sequence, gear material and worm size.

Figure 1 on the following page shows a schematic of the transmission of the KitchenAid Accolade stand mixer (Model \# 4KN15C1X): A motor turns a 10T helical gear $\mathrm{H} 1$ that meshes with a $60 \mathrm{~T}$ helical gear $\mathrm{H} 2$. $\mathrm{H} 2$ is connected through shaft $\mathrm{S} 1$ to a $3 \mathrm{~T}$ worm W. W meshes with 29T worm gear follower WG. WG is connected through shaft $\mathrm{S} 2$ to a $19 \mathrm{~T}$ bevel gear B1 that meshes with a $23 \mathrm{~T}$ bevel gear B2. WG is also connected through shaft S2 to an arm A. Mounted on arm A is shaft S3 with a 20T planet gear P mounted on it. Planet gear P meshes with a fixed $67 \mathrm{~T}$ internal ring gear R. P and R are spur gears. The net gear ratio from motor to arm $\mathrm{A}$ is 58:1. The net gear ratio from the motor to the PTO bevel B2 is 70.2:1.

Figure 2 on the following page shows a schematic of the transmission of the lighter duty KitchenAid Artisan stand mixer (Model \# KSM150PS). Note that sequence of gear stages changed in the Artisan (motor worm to helical to planetary) compared to the Accolade (motor helical to worm to planetary). While similar in components, the cheaper Artisan is not equivalent to the Accolade in ease of disassembly. The Accolade is easier to take apart and put back together, requiring only one screwdriver and snap ring pliers. The Artisan model requires two different screwdrivers, a hammer, two different size hole punches and pliers. Furthermore, the mixer must be substantially disassembled before any parts can be observed or removed. Approximately ten steps (unscrewing etc.) are required before the mechanical gearing is exposed, compared to three steps for the Accolade model. For these reasons, we would not recommend the less expensive versions of stand mixers if a more robust version is available. We would also recommend visiting the KitchenAid site to compare the exploded parts diagrams before choosing a model, and purchasing one trial device before bulk purchases.
Table 1 lists different KitchenAid stand mixers along with model numbers, wattage and transmission type: $\mathrm{W}$ (worm) $\mathrm{H}$ (helical) $\mathrm{P}$ (planetary) as in the lighter duty Artisan, or W (worm) H (helical) P (planetary) as in the heavier duty Accolade.

Table 1. KitchenAid stand mixer comparison. Transmission type: $\mathrm{W}=$ Worm, $\mathrm{H}=$ Helical, $\mathrm{P}=$ Planetary.

\begin{tabular}{|c|c|c|c|}
\hline $\begin{array}{c}\text { Model } \\
\text { Name }\end{array}$ & Model \# & Watts & Trans. type \\
\hline Classic & K45SSWH & 250 & W H P \\
\hline Ultra Power & KSM95WH & 300 & W H P \\
\hline Artisan & KSM150PS & 325 & W H P \\
\hline Pro 500 & KSM500PS & 325 & W H P \\
\hline $\begin{array}{c}\text { Accolade } \\
\text { Professional } \\
5\end{array}$ & KV25H0X & 450 & H W P \\
\hline $\begin{array}{c}\text { Professional } \\
\text { Heavy Duty }\end{array}$ & KG25H0X & 450 & H W P \\
\hline $\begin{array}{c}\text { Professional } \\
600\end{array}$ & KP26M1X & 575 & H W P \\
\hline
\end{tabular}

\section{Laboratory Preparation}

\subsection{Mixer Strip Down}

Prior to the establishment of the lab, 15 mixers were purchased and completely stripped down. A disassembly and re-assembly manual is required, showing step by step instructions with photos. This necessitates the complete disassembly and reassembly of at least one mixer. The complete disassembly of all the mixers was carried for two reasons: 1) Normally, the mixers have $2-4 \mathrm{oz}$ of grease in them. For the purposes of this lab, the bulk of the grease in the mixers has been removed, and the parts wiped clean. 2) Each mixer was individual numbered 1-15 and a different three letter code word was stamped on the inside casing of the mixer below the worm. This number must be recorded by the students to ensure that each team fully dissembles their mixer. The time required for this disassembly, cleaning, stamping and re-assembly (excluding the first mixer) was approximately $1 / 2$ hour per mixer. 

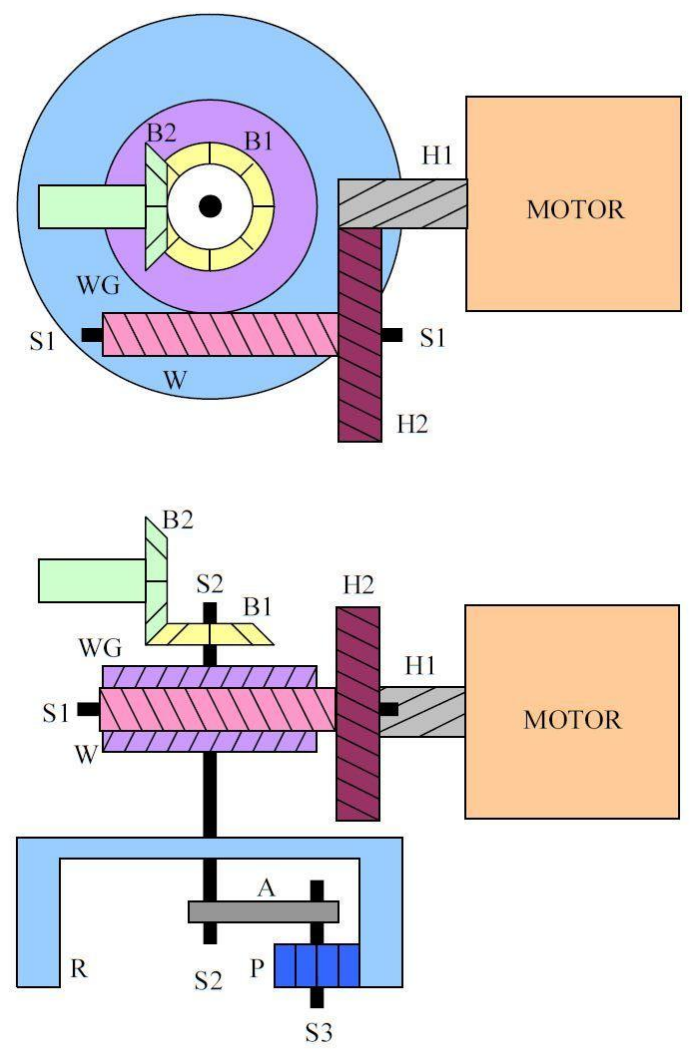

Figure 1. Schematic of KitchenAid Accolade stand mixer (Model \# 4KN15C1X) H W P transmission.

\subsection{Tool sets}

Each group was provided with a small plastic toolbox with a \#2 Robertson or \#2 Phillips screwdriver, plastic calipers, external snap ring pliers, disposable vinyl gloves, paper towel, small paper cups and a step by step disassembly manual. Note that the plastic calipers were inexpensive ( $\sim 1)$ and could only reliably measure to $0.01 "$. More accurate digital calipers could be obtained for approximately $\$ 20$, but the plastic caliper accuracy was sufficient for the measurements required of the lab. Note also that the snap ring pliers tips come to small points and inexpensive versions $(\sim 5-\$ 10)$ are made of softer steel and as such may bend and warp. For this reason, buying slightly more expensive versions would be recommended.

\subsection{Safety}

KitchenAid stand mixer models are high power devices in the 200-400 Watt range with significant torque $(\sim 5-10 \mathrm{~N} \cdot \mathrm{m})$ and as such proper safety precautions and procedures should be undertaken
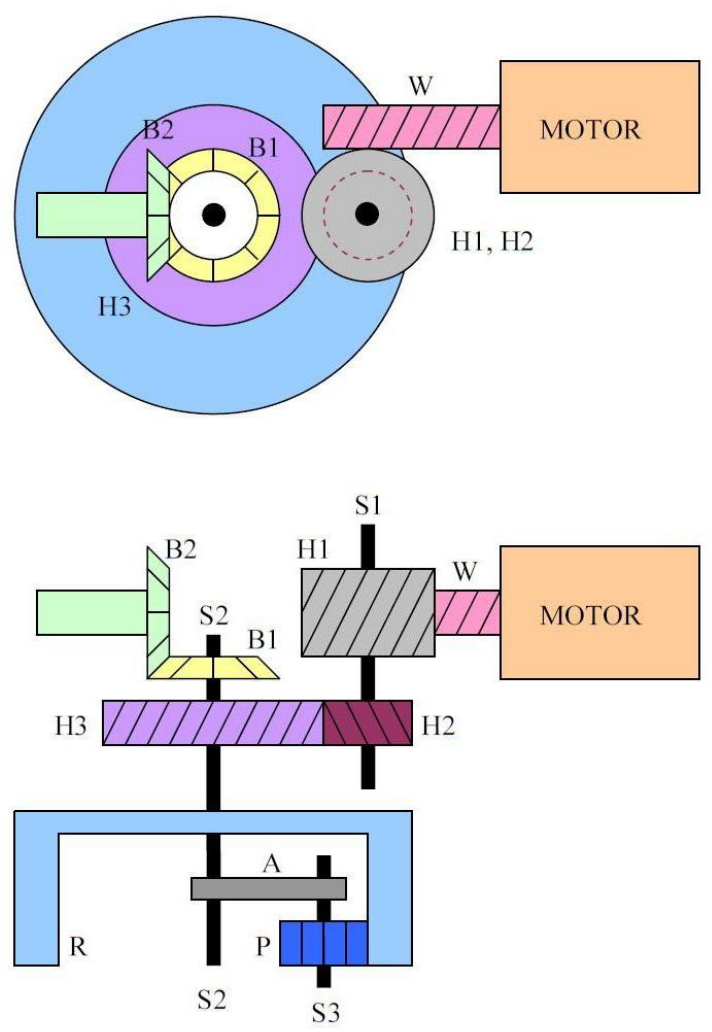

Figure 2. Schematic of KitchenAid Artisan stand mixer (Model \# KSM150PS) W H P transmission.

before students perform the lab. Prior to the lab, a brief safety lecture was given outlining potential hazards and how to avoid them.

The primary risk of injury would come from the misassembly of the mixer and subsequent plugging in of the motor. The frequent check points in the manual make this unlikely (but not impossible). In the single case where a mixer was mis-assembled (see below) no injury occurred. To prevent premature plugging in of the mixer, a zip-tie was placed through the prongs of the plug, which could only be cut after the mixer was inspected. A secondary source of injury could be the accidental pinching or jamming of one student's fingers by another student turning of the gear system. In practice this did not occur as teams generally had only one person at a time handling the parts.

The primary risk of loss or damage to the mixers was: 1) the loss of small parts, particularly the washers, bearings and the snap rings 2) The mixers are top heavy and can fall over unexpectedly, especially when unlocked as students tilt them over to view the underside and measure the planetary ring gear. One mixer was damaged by the Instructor prior to a lab in this fashion but was repaired. 


\section{Laboratory}

\subsection{Disassembly Manual}

Step by step guides to disassembly and reassembling the mixers may be found at the following websites: http://myweb.dal.ca/tjhubbar/KitchenAid_Accolade manual.pdf

http://myweb.dal.ca/tjhubbar/KitchenAid_Artisan_ma nual.pdf

Each step includes colour photos with action arrows and safety warnings where applicable. Some particular steps that may be tricky also visually show the correct and incorrect methods to do the step. Figure 3 shows a few sample pictures from this guide. Production of a disassembly manual from scratch including photos and text is time consuming; approximately 25 hours were required in this case.
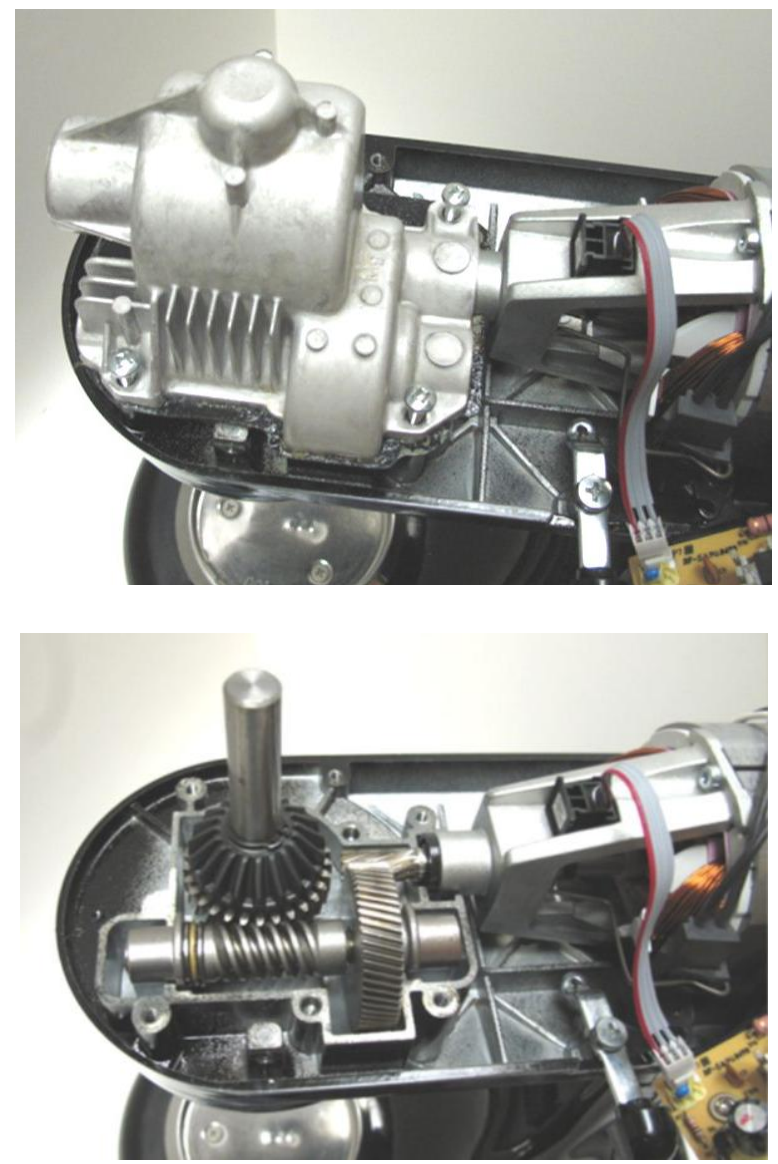

Figure 3. Photos from Accolade KitchenAid mixer disassembly manual. Top: Open case, note heat sink on housing. Bottom: Helical, worm and bevel gear transmissions, note thrust bearing to the left.
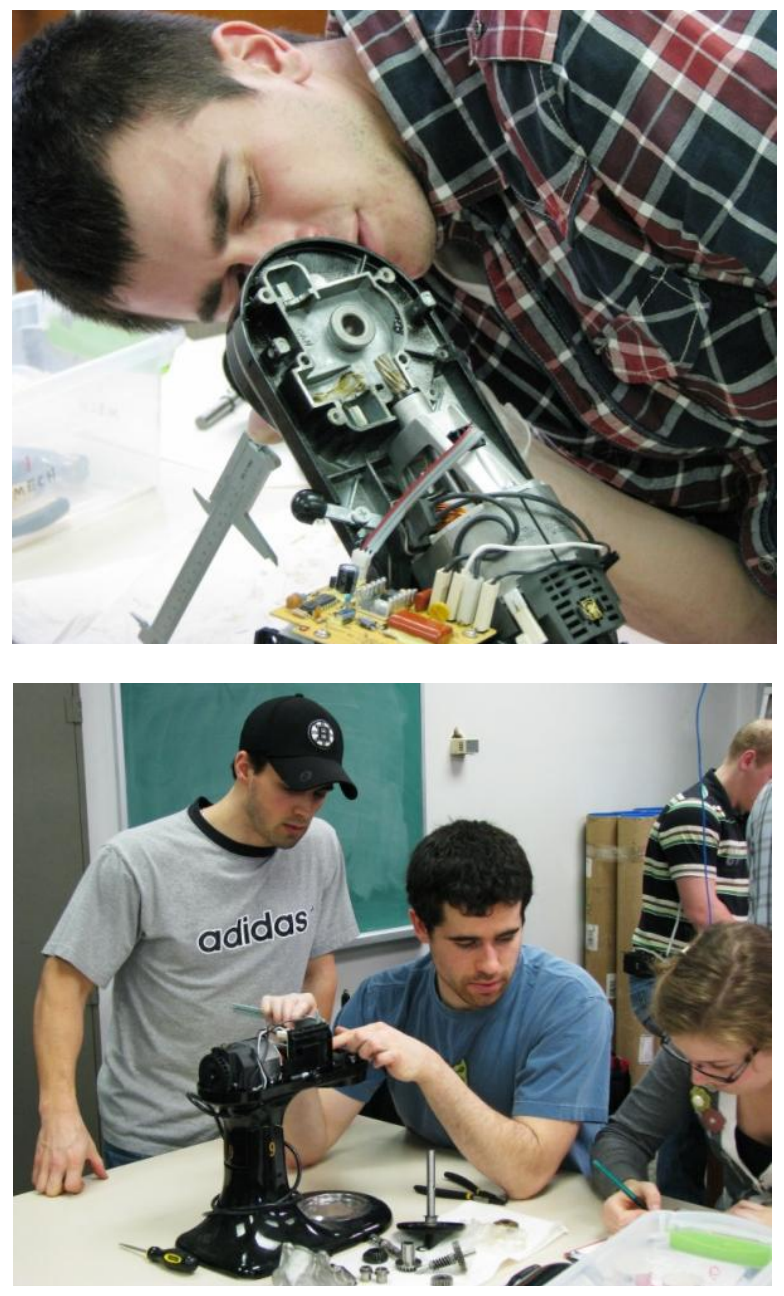

Figure 4. Photos from KitchenAid Accolade mixer disassembly manual. Top: Measuring internal ring gear diameter. Bottom: Measuring helical gear on motor shaft.

\subsection{Measurements and Questions}

Figure 4 shows sample photographs of students taken during the laboratory. During the lab students were required to make a series of measurements of the components as well as count and record the number of teeth on all gearing components and calculate diametral Pitches. Table 2 shows the quantities to be measured as well as the answers.

During the lab students were also asked a series of questions (answers may be found in the Appendix):

1) Why is there a heat sink on the gear housing? Why is it specifically here and not elsewhere?

2) Why is there a thrust bearing located on the worm gear shaft? Why this end and not the other end? 
3) Why is the pitch of the helical gear set significantly smaller than the pitch of the planetary gear set ( 17 vs. 30)

4) Why does the planetary ring gear have a prime number of teeth (67)?

5) How can you accurately measure the circular pitch of the worm follower and the axial pitch of the worm?

Table 2. Student measurements.

\begin{tabular}{|c|c|c|c|c|}
\hline & $\mathrm{N}$ & Do & $\begin{array}{c}\text { Axial/ } \\
\text { Circ. } \\
\text { Pitch }\end{array}$ & $\begin{array}{c}\sim \text { Gear } \\
\text { Pitch } \\
(\mathrm{N}) / \mathrm{D} 0\end{array}$ \\
\hline Helical Pinion & 10 & 0.37 & & 27 \\
\hline Helical Gear & 60 & 1.77 & & 35 \\
\hline Worm & 3 & & 0.17 & \\
\hline Worm Gear & 29 & & 0.17 & \\
\hline Input Bevel & 19 & & & 17.5 \\
\hline Output Bevel & 23 & & & \\
\hline Ring Gear & 67 & 3.84 & & 16.3 \\
\hline Planet & 20 & 1.23 & & \\
\hline
\end{tabular}

\subsection{Model Comparisons}

After completion of the disassembly, but prior to the reassembly, students are asked to compare the interior workings of the Accolade model versus the lighter Artisan model. The students were asked comparison questions (answers may be found in the Appendix):

6) Why is the sequence of gear stages changed in the Artisan (worm to helical to planetary) compared to the Accolade (helical to worm to planetary)

7) Why is the worm much smaller on the Artisan compared to the Accolade?

8) Which of the metal gears on the Accolade could most easily be replaced by a plastic gear in the Artisan?

\subsection{Success Rate}

After filling out the measurements questionnaire and answering at the above questions, the students began reassembling the mixers. Prior to closing the casing, the student mixers were inspected by the Instructor or Teaching Assistant to ensure they had been properly reassembled. The mixers were then re-closed and bought to a separate room away from the other students where they were tested by plugging them in via a long extension cord after cutting the prong safety zip-tie. There were no accidents or injuries sustained by any of the students taking part in the lab.

The lab was run for two consecutive years, in March 2010 and March 2011. Each year had 65 students in 2 sections of 11 groups of 3 students. Of 44 groups total, 43 succeeded in reassembling the mixers the first time. One group reassembled the mixer apparently successfully, but when plugged in and tested, it made a noticeable rattling noise. The students re-opened the mixer and discovered that they had incorrectly placed a spacing washer above a part rather than below it, allowing the part to move. The washer was replaced correctly, the mixer reassembled and found to work properly.

\section{Student Feedback}

Students were polled after completing the lab and asked to agree or disagree with 5 statements. Students would reply to each statement with one of five possible scores: $1=$ Very much disagree, $2=$ Somewhat disagree, $3=$ Unsure, $4=$ Somewhat agree, $5=$ Very much agree. The higher the numerical score the more in agreement the students were with the statement. The statements and the results of the survey including average response out of a possible 5 are shown in Table 3 indicating a high level of interest in the lab.

As examples of the high level of interest, in the first year the lab was offered, several groups declined to leave, even after they had completed the lab, they instead chose to remain and observe other groups. In the second year, one group decided that rather than work as a team they would all take turns disassembling the mixer individually and watch each other do it, so each could do the lab from start to finish. Anecdotally, one sophomore mechanical engineering student thanked the Instructor as "this was the first time I ever took something apart". The lab has also proved popular with non-undergraduates. An additional mixer was setup during the labs and other guests were invited to disassemble their own mixer; participants included graduate students, staff and even faculty and senior administrators. 
Table 3. Student questionnaire responses

\begin{tabular}{|c|c|c|c|c|c|c|}
\hline \multirow[b]{3}{*}{ Statements } & \multicolumn{5}{|c|}{$\begin{array}{l}\text { Number of } \\
\text { Responses }\end{array}$} & \multirow[b]{3}{*}{ Avg } \\
\hline & \multicolumn{5}{|c|}{ Disagree $\rightarrow$ Agree } & \\
\hline & 1 & 2 & 3 & 4 & 5 & \\
\hline $\begin{array}{l}\text { The lab was } \\
\text { engaging and } \\
\text { peaked my interest }\end{array}$ & & 2 & & 5 & 44 & 4.8 \\
\hline $\begin{array}{l}\text { The lab helped me } \\
\text { apply theory to a } \\
\text { practical problem }\end{array}$ & & 1 & 2 & 9 & 39 & 4.7 \\
\hline $\begin{array}{l}\text { Use of the } \\
\text { KitchenAid } \\
\text { allowed for more } \\
\text { hands-on work }\end{array}$ & 1 & & & 1 & 49 & 4.9 \\
\hline $\begin{array}{l}\text { Overall, this lab } \\
\text { increased } \\
\text { understanding of } \\
\text { the topic }\end{array}$ & & 1 & 2 & 15 & 33 & 4.5 \\
\hline $\begin{array}{l}\text { I would like more } \\
\text { labs of this type }\end{array}$ & 1 & & 1 & 1 & 48 & 4.8 \\
\hline
\end{tabular}

\section{Budget}

The cost was approximately $\$ 600 \mathrm{CDN}$ per setup (taxes included):

\begin{tabular}{|c|c|}
\hline KitchenAid Accolade: & $\sim \$ 500$ \\
\hline KitchenAid Artisan: & $\sim \$ 300$ \\
\hline $\begin{array}{l}\text { Toolset: } \\
\text { Screwdrivers,Snap Ring Pliers, } \\
\text { Pliers, ,Plastic Calipers, } \\
\text { Plastic Toolboxes, Gloves }\end{array}$ & $\sim \$ 20$ \\
\hline $\begin{array}{l}\text { Labour costs: } \\
\text { Disassembly, } \\
\text { cleaning, } \\
\text { stamping, } \\
\text { re-assembly } \\
\text { Manual preparation }\end{array}$ & $\sim \$ 1,300 \quad(* 1)$ \\
\hline $\begin{array}{l}\text { Spare parts: } \\
\text { 1-4 counts of small parts } \\
\text { most likely to be lost: } \\
\text { Retaining Clips, Thrust Bearing, } \\
\text { Front Bearing, Rear Bearing. }\end{array}$ & $\sim \$ 150 \quad(* 1)$ \\
\hline $\begin{array}{l}\text { Total } \\
\text { Cost per setup }\end{array}$ & $\begin{array}{l}\sim \$ 9,000 \\
\sim \quad \$ 600\end{array}$ \\
\hline
\end{tabular}

\section{Conclusion}

This paper presented a Mechanical Dissection Laboratory based on a KitchenAid stand mixer. The laboratory has been run for two consecutive years with high levels of student interest. This laboratory could also be adapted beyond Machine Design aspects for use with electrical/materials topics as well.

\section{APPENDIX}

Answers:

1) The worm gear generates heat through friction and the heat sink is located directly above it.

2) The worm gear experiences axial forces and based on the motor rotation direction and the helix angle, tends to be pushed away from the motor.

3) The planetary gear experiences more torque.

4) The prime number means that the gear ratio (67/20) has no common factor and that 67 cycles are required to return to the same point, ensuring that there are no large unmixed areas. The manufacturer promotes this feature on the box.

5) Students discovered that if you coat the worm and follower with grease and roll them on a paper towel, the resultant grease mark can be more easily measured with the calipers.

6) Unknown.

7) By moving the worm closer to the motor and placing the helical gears after it, the torque on the worm is reduced by $6 \mathrm{x}$.

8) The helical gear closest to the motor experiences the least torque and is most easily replaced.

\section{Acknowledgments}

The authors would like to thank Dr. T. Little for his assistance in this laboratory. The authors would like to thank Dr. J. Leon and Dr. P. Cyrus for their financial support of this project.

\section{References}

[1] Shigley, J. E., \& Mischke, C. E. (1989). Mechanical Engineering Design (5th ed.). New York, United States of America: McGraw-Hill.

[2] Sheppard, S. D. (1992). Mechanical Dissection: An experience in how things work. Proceedings of the Engineering Education: Curriculum Innovation \& Integration. Santa Barbara.

[3] KitchenAid Website [Online] [Cited: April 26, 2011] http://kitchenaid.ca 